Meta

Journal des traducteurs

Translators' Journal

\title{
The Unit of Translation: Statistics Speak
}

\section{Harry J. Huang et Canzhong Wu}

Volume 54, numéro 1, janvier 2009

URI : https://id.erudit.org/iderudit/029796ar

DOI : https://doi.org/10.7202/029796ar

Aller au sommaire du numéro

\section{Éditeur(s)}

Les Presses de l'Université de Montréal

ISSN

0026-0452 (imprimé)

1492-1421 (numérique)

Découvrir la revue

Citer cet article

Huang, H. J. \& Wu, C. (2009). The Unit of Translation: Statistics Speak. Meta, 54(1), 110-130. https://doi.org/10.7202/029796ar

\section{Résumé de l'article}

Les auteurs ont mené une étude visant à caractériser l'unité de traduction (UT), un sujet de débat depuis plus de quarante ans. L’article présente un état de la question, une redéfinition de l'UT, une analyse d'un échantillon de textes, de passages et de phrases traduits extraits d'un corpus de plus de 23000 pages, y compris la Bible et Soul Mountain, traduit du roman de Gao Xingjian, lauréat chinois du prix Nobel de littérature, et, enfin, les résultas d'une enquête internationale. La comparaison de textes de départ (ST pour source text) et des textes traduits (TT) montre que les traductions sont effectuées phrase par phrase, en contexte, ce qui fait de la phrase en contexte l'unité de traduction. Ce constat est confirmé par une enquête internationale de 66 traducteurs et réviseurs professionels de traductions. La vérification de la nature de l'UT réalisée dans la présente étude indique que pour qu'une théorie faisant référence à l'UT soit testable, les théoriciens de la traduction ne peuvent plus isoler la phrase de son contexte.
Ce document est protégé par la loi sur le droit d'auteur. L'utilisation des services d’Érudit (y compris la reproduction) est assujettie à sa politique d'utilisation que vous pouvez consulter en ligne.

https://apropos.erudit.org/fr/usagers/politique-dutilisation/ 


\title{
The Unit of Translation: Statistics Speak
}

\author{
HA R RY J. H UANG \\ Macquarie University, Sydney, Australia \\ harry8899@yahoo.com \\ CANZHONG W U \\ Macquarie University, Sydney, Australia \\ canzhong.wu@ling.mq.edu.au
}

\begin{abstract}
RÉSUMÉ
Les auteurs ont mené une étude visant à caractériser l'unité de traduction (UT), un sujet de débat depuis plus de quarante ans. L'article présente un état de la question, une redéfinition de I'UT, une analyse d'un échantillon de textes, de passages et de phrases traduits extraits d'un corpus de plus de 23 ooo pages, y compris la Bible et Soul Mountain, traduit du roman de Gao Xingjian, lauréat chinois du prix Nobel de littérature, et, enfin, les résultas d'une enquête internationale. La comparaison de textes de départ (ST pour source text) et des textes traduits (TT) montre que les traductions sont effectuées phrase par phrase, en contexte, ce qui fait de la phrase en contexte l'unité de traduction. Ce constat est confirmé par une enquête internationale de 66 traducteurs et réviseurs professionels de traductions. La vérification de la nature de l'UT réalisée dans la présente étude indique que pour qu'une théorie faisant référence à l'UT soit testable, les théoriciens de la traduction ne peuvent plus isoler la phrase de son contexte.
\end{abstract}

\section{ABSTRACT}

The authors have conducted a study aiming at determining the unit of translation (UT), a subject of debate for more than forty years. The article consists of a review of relevant literature, a redefinition of the UT, an examination of sampled translated texts, excerpts and sentences of over 23,000 pages, including the Bible and Soul Mountain, translated from the Nobel Prize-winning novel of the Chinese author, Gao Xingjian, and an international survey. The contrastive analysis of these ST and TT materials shows that translations are done sentence by sentence within context and thus identifies the sentence in context as the UT. This identification is further confirmed by an international survey of 66 professional translators and translation editors. By verifying the UT, this study indicates that for a UT-related theory to be testable, the translation theorist should no longer ignore or sideline the sentence from its context.

\section{MOTS-CLÉS/KEYWORDS}

unit of translation/translation unit (UT), sentence in context, translation quality assessment (TQA), translation studies, translatology

\section{Objective of the study}

This study attempts to (1) redefine the unit of translation (UT), (2) identify the unit of translation through contrastive analysis of a random selection of published translations, and (3) compare findings with the UT used by international translators. 


\subsection{Definitions of the unit of translation}

The UT, which has various interpretations, has been a subject of debate since it was raised and defined by Vinay and Darbelnet in 1958 (Nord [1997] 2001: 68). According to them (1958/1995: 21), the UT is "the smallest segment of the utterance whose signs are linked in such a way that they should not be translated individually." Hatim and Munday simply call it "normally the linguistic unit which the translator uses when translating" (2004: 25). Snell-Hornby (1988/1995: 16) calls the UT "a cohesive segment lying between the level of the word and the sentence." UTs claimed by scholars range from the culture of the language to the whole text to the morpheme, with Newmark alleging that "all lengths of language can, at different moments and also simultaneously, be used as units of translation [...]," but "operatively, most translation is done at the level of the smaller units (word and clause)" (1988: 66-67). Guo Jianzhong, based on his own experience, claims that in Chinese-English translation "the best UT is the paragraph" (2002: 544). Like other translation theories, these are scholarly opinions. Since the first definition of UT was given some fifty years ago, translation scholars have been interpreting and repeating it, but in-depth analysis of translations is unheard of.

Developing translation theory, especially translation quality assessment (TQA) models without knowing the UT is no different from studying medicine without knowledge of the human cell. Success is possible but may be accidental. Identifying the UT is an attainable task, though not by repeating old definitions and citing confusing opinions. Two favorable conditions have long existed, which are the abundance of translations available in public libraries and bookstores, and the large number of professional translators throughout the world. The UT should not have been defined by scholars in the first place, but should have been synthesized from practice. A sample of translations and a survey conducted among the latter could have identified the UT five decades ago.

Instead of jumping into Vinay and Darbelnet's over-interpreted definition or its various confusing versions, all of which are primarily set within the context of ST, the authors identify the UT through an analysis of sampled translated texts, excerpts and sentences of over 23,000 pages, and confirm it with an international survey among 66 professional translators.

\subsection{Definition of UT adapted}

Matthiessen, among other scholars, assumes that "[...] the clause (complex) [sentence as called in traditional grammar] is a likely candidate as the 'unit of translation' [...]" (2001: 116). We agree, and we further define UT as a TT segment instead of the commonly accepted ST segment, as follows: (1) the UT creates an interval in the translating process, (2) it is into which the translator renders from the ST, (3) it has distinct and consistent grammar features, and (4) it possesses presence of meaning which is identifiable, and accuracy which is measurable through standardized assessment. In summary, the UT bears universal features, plays a consistent role in the construction of translation, and has measurable meaning. The UT may have a co-UT (ST) that has the same or different syntax features and whose meaning comes from the same or different linguistic units. In other words, a TT sentence may be a translation of a ST 
sentence, or a clause of a sentence, or two clauses, two parts of two ST sentences, or a sentence and part of another sentence.

\subsection{Methodology}

\subsubsection{Non-primary data}

The Holy Bible, one of the most carefully translated works, the Koran, the Nobel Prize-winning novel Soul Mountain, and other bilingual or multilingual texts as well as poetry are sampled for analysis for the identification of the UT.

\subsubsection{Selection method}

Samples are randomly selected, ranging from complete texts to single sentences. In most cases, randomly-selected pages or passages are examined. The sample selected for analysis is Page/Chapter 30 when possible, or the first complete sentences of the randomly selected pages, or text chosen through other random methods. Whatever is selected is intended to represent the translation without bias. Due to limited space, each sample discussed in this paper is kept as brief as possible. The twenty-one tables, except Tables 5 and 6, illustrate only one feature of the TT, namely, one or two types of punctuation marks in most cases. It is not suggested that punctuation marks alone may accurately reflect the quality of a TT. It is reminded that the punctuation marks are a component of acceptable translations, and that the paramount goal of this study is to identify the UT. Punctuation marks are standard features shared by the great majority of the languages in the world. For example, one full-stop may equal one sentence in most cases, though a small number of languages (e.g. Thai) do not indicate the end of the sentence with a period. In our study, wherever the punctuation marks are presented, they are to be interpreted accordingly.

\subsection{Primary data}

Between September 2005 and July 2006, the authors conducted an international survey to identify the UT used by professional/published translators including translation editors and translation professors at universities and colleges. A call for participation was launched at gatherings attended by translators and editors organized by the Chinese Pen of Canada, and by the KCLK-21 Publication. Reputed translators were also directly contacted by the authors and recommended by peers. Sixty-six copies of the survey were completed by qualified participants from America, Australia, Canada, China, other countries in Asia and Europe, and elsewhere. A second survey was conducted among 30 professional writers to uncover the unit of writing and editing, while a third one was completed by 75 university and college student writers in the Toronto area including attendees of the University of Toronto, also, to identify the unit of writing in comparison with that of the professionals. 


\section{Analysis of Translation Samples}

\subsection{Types of translation analyzed}

The study includes samples of literature, non-literary works as well as academic works. Literature is often considered the most complex text type. As Nord puts it, "it seems sensible to take the most complex text type as a starting point" (1991: 2). Though academic translation can also be classified under non-literary texts, it is separated into an independent category merely to highlight its importance. The samples studied were taken from (1) non-literary texts: government documents, legal and religious texts including the Bible and the Koran, as mentioned above; (2) academic translation: research papers, examples of translation furnished in translation studies; (3) literary translation: poetry, plays, essays, novels, including Shakespeare's Macbeth, and author-translated text, and a bilingual work for comparative purposes.

\subsection{Analysis of non-literary translation samples}

\subsubsection{The United Nations Universal Declaration of Human Rights (UDHR)}

As of April 2006, the UDHR which was originally written in the six official languages had been translated into 326 languages, making it available in 332 (United Nations, 2006). A sample of three articles (10,11 and 12) in nineteen languages including the six United Nations official languages is selected for examination. The number of sentences in each of the TTs is listed below.

TABLE 1

Sentence arrangements in TTs of Articles 10, 11 and 12 of the UDHR

\begin{tabular}{|l|l|l|l|}
\hline \multicolumn{2}{|l|}{ Language } & Articles & Sentences \\
\hline Non-UN Official & UN Official & 3 & 6 \\
\hline & English & 3 & 6 \\
\hline & French & 3 & 6 \\
\hline & Chinese & 3 & 6 \\
\hline & Spanish & 3 & 6 \\
\hline & Russian & 3 & 6 \\
\hline Albanian & Arabic & 3 & 6 \\
\hline Bikol/Bicolano & & 3 & 6 \\
\hline Dagaare & & 3 & 6 \\
\hline Frisian & & 3 & 6 \\
\hline Huasteco & & 3 & 6 \\
\hline Kazakh & & 3 & 6 \\
\hline Lingala & & 3 & 6 \\
\hline Mende & & 3 & 6 \\
\hline Oshiwambo (Ndonga) & & 3 & 6 \\
\hline Rhaeto-Romance (Rumantsch) & & 3 & 6 \\
\hline Solomons Pidgin (Pijin) & 3 & 6 \\
\hline Tok Pisin & & 3 & 4 \\
\hline Yapese & & 3 & 6 \\
\hline
\end{tabular}

The analysis indicates that the UDHR has been translated sentence by sentence, article by article, with the original format, sentence order, and meaning closely 
followed. None of the languages sampled have changed, reduced, or increased the number of the original articles. All of them show the same articles translated into the same number of sentences, except Solomons Pidgin (Pijin) that condensed the ST six into four in the TT, which, nevertheless, reveals no alteration of meaning.

\subsubsection{The Holy Bible}

Except in rare cases where the regional Bible societies cannot or do not have the authority to edit the text, as in the case of the Chinese TSPM and CCC that have printed a bilingual version of the Chinese Union Version with New Punctuation without adjusting the discrepancies of verses that were translated from different sources (Greek original versus Hebrew original), comparative analysis indicates that all the following biblical texts have been translated sentence by sentence within the context of the Bible: (1) The New Testament of Our Lord and Saviour Jesus Christ (1899) (in Greek and English) - 83 pages of 640 selected for analysis, (2) The Interlinear GreekEnglish New Testament (1960) - 64 pages of 1027 sampled, (3) The New Greek-English Interlinear New Testament (1990) - 34 pages of 913 selected, (4) The Septuagint Version of the Old Testament and Apocrypha with an English Translation; and with Various Readings and Critical Notes - 69 pages sampled out of 1378 analyzed, (5) The Parallel New Testament in Greek, Chinese [four versions], and English (PNT) - entire text of 749 pages examined, (6) Holy Bible: King James Version in English and Chinese - entire text of 1891 pages compared, and (7) Holy Bible: New Revised Standard Version (in simplified Chinese and English) - complete text of 1993 pages analyzed. Following are the results of a sample taken from the Parallel New Testament (United Bible Societies, 1997: 30-31) with “TT2: Chinese V. 1b" from another version in English and simplified Chinese (National TSPM and CCC, 1997) added for comparative purposes.

TABLE 2

\section{Sentence arrangements in the sample page of the PNT}

\begin{tabular}{|l|l|l|l|}
\hline Languages & Sentences, or end marks & Semicolons & Total \\
\hline ST: Greek & 19 & 8 & 27 \\
\hline TT1: Chinese V. 1a & 22 & 14 & 36 \\
\hline TT2: Chinese V. 1b & 24 & 9 & 33 \\
\hline TT3: Chinese V. 2 & 23 & 11 & 34 \\
\hline TT4: Chinese V. 3 & 22 & 15 & 35 \\
\hline TT5: Chinese V. 4 & 20 & 15 & 35 \\
\hline TT6: English & 19 & 14 & 33 \\
\hline
\end{tabular}

TT1 and TT2 are the same version of Chinese translation except that the former is in fanti (traditional Chinese characters) while the latter is in jianti (simplified Chinese characters). As indicated in the table, when the jianti version was converted from the original fanti edition, the number of sentences changed from 22 to 24 while the semicolons, from 14 to 9, but the examination of the two pages listed above shows no change in meaning or in words. Analysis indicates that translators often convert into sentences independent clauses with a subject-verb unit.

The mean of the sentences in the five versions of Chinese translation and the English and that of independent clauses of the six translations are tabulated below. 
TABLE 3

Mean of sentences and independent clauses in TT sample pages of the PNT

\begin{tabular}{|l|l|l|l|l|l|l|}
\hline \multirow{2}{*}{ Features } & \multirow{2}{*}{$\mathrm{T}$} & \multirow{2}{*}{ Df } & \multirow{2}{*}{$\begin{array}{l}\text { Sig. } \\
(2 \text {-tailed })\end{array}$} & \multirow{2}{*}{$\begin{array}{l}\text { Mean } \\
\text { Difference }\end{array}$} & \multicolumn{2}{|l|}{$\begin{array}{l}\text { 95\% Confidence Interval } \\
\text { of the Difference }\end{array}$} \\
\cline { 6 - 8 } & & & & Lower & Upper \\
\hline Sentences or end marks & 28.504 & 5 & .000 & 21.66667 & 19.7127 & 23.6206 \\
Semicolons & 13.000 & 5 & .000 & 13.00000 & 10.4294 & 15.5706 \\
\hline
\end{tabular}

The source text of the sample page contains 19 end marks and 8 semicolons, totaling 27, while the average of the six translations, 22 sentences which include 13 clauses with semicolons, the nature of which implies that the TT could be interpreted as 35 sentences or independent clauses. Though the mean total, accepted as such, shows a difference of eight, all the six translations consistently adhere to the order of the ST sentence by sentence and in most cases clause by clause, within the sentences. The ST meaning has by and large been translated.

\subsubsection{The Koran}

An analysis of Pickthall's English translation (Eliyasee and Pickthall 2001) in the Arabic-English work of 605 pages and Ali's The Glorious Qur'ân Translation of 423 pages (1999), Ali's other version The Meaning of the Glorious Qur'ân Translation [with new punctuation] (2002), and Nadvi's French translation Le Saint Coran (2001) demonstrates that the translations were rendered sentence by sentence, or rather, verse by verse. Verse 30 of "Surah 30" (Ali 1999: 266; Ali 2002: 283) is sampled for comparison with the ST as well as with Eliyasee and Pickthall's English translation (2001: 401) and with Nadvi's French translation (2001: 293). The following table shows the TT arrangements.

TABLE 4

TT sentence arrangements of Verse 30 of "Surah 30" of the Koran

\begin{tabular}{|l|l|l|l|}
\hline Translation & Verses & Sentences & Other features \\
\hline ST & 1 & $1(?)$ & (No end mark) \\
\hline TT1: Ali, 1999 & 1 & 1 & 3 colons \\
\hline TT2: Ali, 2002 & 1 & 3 & 1 colon \\
\hline TT3: Eliyasee and Pickthall, 2001 & 1 & 3 & 2 dashes \\
\hline TT4: Nadvi, 2001 & 1 & 1 & 1 colon, 1 semicolon, and 2 dashes \\
\hline
\end{tabular}

The analysis shows that all the translations transfer the ST meaning as interpreted by the translators, following the ST syntax closely. The difference between Ali's 1999 version and 2002 version deserves further mention. As indicated in the table above, Ali follows the ST strictly in the 1999 translation, but it seems much harder to read and understand. His 2002 edition is re-punctuated, appearing to significantly improve readability. The result is that he uses three sentences instead of one but reduces the use of colons from three to one. His new edition also shows a change in the last clause, namely, "but most among mankind do not understand" has been changed to "but most among mankind understand not." Pickthall's translation reveals some difference in the understanding of the original text, but regardless 
of the differences, including those in the French translation, all the TTs have been translated following the ST syntax closely. The UT is the sentence.

\subsubsection{The Lun $\mathrm{Yu}$ [Analects, 499 sayings]}

Confucius Publishing has released the translation of The Lun Yu [Analects, 499 sayings] by Confucius in twenty-three languages, two of which are fanti Chinese and jianti Chinese, as detailed by the publisher. The ST in ancient Chinese has been rendered either phrase by phrase or sentence by sentence, but the UT is clearly the sentence. An example of the English translation is provided below (Confucius Publishing, 2006, Chapter 7, Verse 6):

TABLE 5

\section{Comparison of sentence structure between ST, the ancient Chinese, and TT}

\section{[ST: traditional Chinese in pinyin]}

Zi yue: zhi yu dao, ju yu de, yi yu ren, you yu yi.

[TT]

Confucius said,

"Aspire to the way, align with virtue, abide by benevolence, and immerse yourself in the arts."

${ }^{1}$ The six arts: rites, music, archery, charioteering, language and mathematics.

Each translation comes with the original Chinese on top of it. In the example above, every three Chinese characters are translated into a verbal phrase: "Zhi yu dao" is translated into "Aspire to the way," " ju yu de," into "align with virtue," " $y i$ yu ren," into "abide by benevolence," and "you yu yi," into "immerse yourself in the arts." The necessary conjunction "and" is added, and so is the note. These four verbal phrases make up the saying. The unit of this translation is the saying, or grammatically the sentence. The translations of the other languages have been completed in the same fashion. Full texts are available for comparison at Confucius Publishing's website: www.confucius.org.

\subsubsection{The Canadian Charter of Rights and Freedoms (CCRF) in English and French}

The CCRF (Department of Justice, 1982) is one of the numerous government documents that have been and are still being published in Canada by the federal government and various provincial governments. On an annual basis, the Canadian Language Quality Measurement System alone assesses the quality of 300 million words of translation (cf. Williams, 2004: 3), ranging from law to reports, anything the governments need to publish. The authors' contrastive analysis indicates that more than $99 \%$ of what they have read has been translated sentence by/for sentence. It is usually hard to tell whether the Canadian bilingual documents are translated from French to English, or vice versa. The following is an example, taken from Part 1 of the CCRF. 
TABLE 6

Comparison of sentence structure between English and French of CCRF

[English]

10. Everyone has the right on arrest or detention

a) to be informed promptly of the reasons therefore;

b) to retain and instruct counsel without delay and to be informed of that right; and

c) to have the validity of the detention determined by way of habeas corpus and to be released if the detention is not lawful.

[French]

10. Chacun a le droit, en cas d'arrestation ou de détention:

a) d'être informé dans les plus brefs délais des motifs de son arrestation ou de sa détention;

b) d'avoir recours sans délai à l'assistance d'un avocat et d'être informé de ce droit;

c) de faire contrôler, par habeas corpus, la légalité de sa détention et d'obtenir, le cas échéant, sa libération.

Note that the leading clause in the French version has a colon that is not found in the English version. Such are the differences one may find in Canadian bilingual documents. Nevertheless, the Canadian government's official documents nearly always show the following features:

- ST and TT carry the same meaning with the same linguistic power and effect as the pairing language;

- Formal language is employed, though popular reading materials may use casual language;

- The two texts appear parallel in

- headers, cardinal numbers, most punctuation marks, etc.,

- paragraphing,

- number of sentences,

- syntax comparability.

All these may be found in the example above.

\subsubsection{Patent Law of the People's Republic of China (in Chinese and English) (PLPRC)}

The English translation Patent Law of the People's Republic of China indicates the same approach to translation as that of the Canadian government's documents. A review of Article 30 (Government of China: 1992: 14-15, 51) reveals the following:

TABLE 7

Comparison of sentence structure between ST and TT of the PLPRC

\begin{tabular}{|l|l|l|l|l|}
\hline Languages & Sentences & Independent clauses & Punctuation \\
\hline Chinese & 1 & 2 & 1 period and 1 semicolon & 3 commas \\
\hline English & 1 & 2 & 1 period and 1 semicolon & 4 commas \\
\hline
\end{tabular}

As the table indicates, the English translation has been rendered sentence for sentence following the ST syntax closely. The article contains one compound sentence with two subordinate clauses, each of which has its own subordinate clauses. A rather complex sentence structure has been used (though the words are relatively simple) 
in order to render the article into one English sentence to match the ST. The comparison of this law, among others, indicates that Chinese legal documents are translated into English sentence by sentence.

\subsection{Academic translations - a summary}

Analysis of translation in academic publications also indicates a sentence-for/bysentence approach. Evidence is not only found in complete works, but also in examples of translation used by translation scholars. Wu's 32-page Chinese translation of Halliday's "Computing Meanings: Some Reflections on Past Experience and Present Prospects" (Halliday [au.] and Wu [tr.], 2002: 1-31) not only follows the ST sentences closely, but also the order and layout of the ST paragraphs. Pollard's English translation "Writing to Defame" in Chinese Translators' Journal has also been rendered sentence for/by sentence (Zhou [au.] and Pollard [tr.], 2004: 91-93). The ST "Le crime aurait-il des soubassements?" and its TT "Is Crime Built on Solid Foundations?" selected for the testing of Williams' TQA model (Williams 2004: 95-103) also demonstrate the sentence-by/for-sentence approach to French-English and EnglishFrench translation. These and other samples of translation furnished by numerous other translator scholars (e.g. Hatim and Mason 1990: 224-226; Feng 2002: 198-341; Lederer 2003: 72-73), indicate that the UT is the sentence. The reader is invited to directly verify these examples in the original texts.

\subsection{Analysis of literary translation excluding poetry}

\subsubsection{Soul Mountain}

Soul Mountain (Gao, 2000b), translated by Mabel Lee from Gao Xingjian's Chinese Nobel Prize-winning novel Ling Shan (Gao, 2000a), demonstrates that the 506-page TT was completed sentence by sentence. An ST sentence may have been rendered into two or more English sentences. By the same token, more than one ST sentence may have been combined and translated into one English sentence. In other words, a component, often a clause, may be translated into an English sentence while a ST sentence may be rendered into a clause. A comparison of the use of periods, semicolons, commas and dashes of the ST and TT of the first page of Chapter 30 (Gao 2000b: 167-168) provides a glimpse of the features of TT sentence structure:

TABLE 8

Comparison of ST and TT of Soul Mountain through analysis of punctuation

\begin{tabular}{|l|l|l|l|l|}
\hline Languages & Periods & Semicolons & Commas & Dashes \\
\hline ST: Chinese & 9 & 0 & 28 & 0 \\
\hline TT: English & 13 & 0 & 11 & 1 \\
\hline
\end{tabular}

As shown in the table, the number of TT periods and commas differs significantly from that of the ST. What should be noted is that the ST usage of the comma may have contributed much to the difference. While a comma is seldom used without a conjunction to separate two coordinate clauses in English, it is grammatically correct to use the Chinese comma to separate not only subordinate clauses in a complex 
sentence, but also coordinate clauses within compound sentences (cf. Huang 1986: 49; $\mathrm{Su}$ 1999: 54). As commonly found, many Chinese commas are used in the same way as English semicolons. Six of the ST commas seem to have been interpreted as periods, which could be one of the reasons why the translation has more sentences than the Chinese text. In two instances, for fluency or other reasons, two ST sentences were combined with a third one. An addition of five and a reduction of two result in thirteen sentences in the TT. Nevertheless, Lee follows the ST closely. Except for sentence combining, splitting, and the reverse order of words, word groups, and clauses, she follows the ST sentence by sentence. Hardly can one find an instance of sentence relocation. Lee translates by the sentence within the context of the novel, limiting the freedom of re-creativity mostly to the sentence. The contrastive analysis indicates little difference in the approaches taken by Lee and translators of non-literary texts.

\subsubsection{Journey to the West}

One of the most-beloved literary pieces in China, Xi You Ji (Journey to the West), has been translated by Jenner, among others, into English (Wu 1990). The 933-page ST has been rendered into 1858 pages in English. Analysis of samples (Wu 1990: 1800) shows that the TT follows the ST closely, in the original order of narration or events described.

TABLE 9

ST and TT sentence arrangements in Journey to the West

\begin{tabular}{|l|l|l|l|l|}
\hline \multirow{2}{*}{ Languages } & \multirow{2}{*}{ Sentences } & Punctuation & \multicolumn{2}{|l|}{} \\
\cline { 3 - 5 } & & Commas & Semicolons & Colons \\
\hline ST: Chinese & 15 & 21 & 0 & 1 \\
\hline TT: English & 15 & 12 & 7 & 0 \\
\hline
\end{tabular}

As revealed in the table above, the TT contains the same number of sentences as the ST. Analysis shows that while additional semicolons and fewer commas are used in the TT, they do not change the fundamental structure of the TT sentences. Except for the re-arrangement of the first two sentences of page 1800, the TT appears to have followed the ST in the following aspects: (a) sentences, (b) clauses, (c) phrases, (d) poetic lines, and (e) end marks.

It should be noted that this sample also contains a poem, which has also been translated sentence by sentence, or rather, line by line or couplet by couplet.

\subsubsection{Pu Songling's Liao Zhai Zhi Yi}

The short-short stories written by the world-renowned Pu Songling have been translated into English. Rose Quong, for one, translated forty of his works (P'u [Pu], 1946). Despite a lack of translation theory in the 1940s, Quong's English translations were successful, and by today's standard, they are still of high quality. The first page of "The Fox Maiden Lien Shiang" (P'u [Pu], 1946: 27) is sampled for analysis regarding her approach to the treatment of ST sentences. The following table, through an analysis of three punctuation marks, indicates the differences in the sentence structure of ST and TT. 
TABLE 10

ST and TT sentence arrangements in Pu Songling's "Lien Shiang”

\begin{tabular}{|l|l|l|l|l|}
\hline \multirow{2}{*}{ Languages } & \multirow{2}{*}{ Sentences } & Punctuation & \multicolumn{2}{|l|}{} \\
\cline { 3 - 5 } & & Commas & Semicolons & Colons \\
\hline ST: Chinese & 8 & 20 & 0 & 3 \\
\hline TT: English & 12 & 10 & 3 & 4 \\
\hline
\end{tabular}

The ST contains eight sentences, while the TT, twelve with three semicolons present as well as four colons preceding direct speech. Four of the commas in the ST seem to have been interpreted as semicolons by the translator. Apart from the formal differences between the ST and TT, the following are observed:

- A cultural point, ming and $z i$ are combined into "name" only, losing the translation of the character's name - Xiao. In ancient China, ming was the given name, while $z i$, often another name indicating the moral aspect or fine personality of the name bearer. There is no equivalent in English, and for literature, such a loss causes no practical harm, and perhaps may be better left out to improve style.

- The translator follows the ST closely, resulting in sentences that may contain as many as four clauses which she separates, except for one, into shorter coordinate clauses each containing two sub-clauses or less.

- All the TT sentences follow those of the ST one by one. Where sentences contain three or more verbs, the translator identifies the independent ones for new sentences or independent clauses. Nevertheless, syntactically and semantically ST sentences are rendered directly where possible.

\subsubsection{Utopia}

Utopia available in a Latin-English version (More, 1965) has been translated into Chinese (Dai, 1982). The Chinese, believed to be a translation of the English, was done sentence by/for sentence, or from clause (independent), or CI, into sentence, or vice versa. This approach is clearly demonstrated by the 133-page Chinese translation when it is compared with the English text of the 202-page bilingual Latin-English original. Page 30 of the Chinese translation, including the seven characters on the next page, shows the following against the English:

TABLE 11

Comparative analysis of English and Chinese sentence structure of Utopia

\begin{tabular}{|l|l|l|l|l|}
\hline \multirow{2}{*}{ Languages } & \multirow{2}{*}{ Sentences } & Punctuation & \multicolumn{2}{|l|}{} \\
\cline { 3 - 5 } & & Commas & End marks & Semicolons and colons \\
\hline English & 19 & 17 & 19 & 0 \\
\hline Chinese & 20 & 31 & 20 & 1 \\
\hline
\end{tabular}

\subsubsection{Ma Ke Bai (Zhong Ying Dui Zhao) (Macbeth in English and Chinese)}

The 175-page Ma Ke Bai (Zhu [tr.], [1944]1996: 30), a Chinese translation of William Shakespeare's Macbeth, was rendered sentence by sentence, or CI by CI, or line by line, following the order of the ST acts and scenes. Page 30 of $\mathrm{Ma} \mathrm{Ke} \mathrm{Bai} \mathrm{is} \mathrm{sampled}$ for analysis: 
TABLE 12

Sentence arrangements of Zhu's Chinese translation of Macbeth

\begin{tabular}{|l|l|l|l|l|}
\hline \multirow{2}{*}{ Languages } & Sentences & Punctuation & \multicolumn{2}{|l|}{} \\
\cline { 3 - 5 } & & Commas & End marks & Semicolons and colons \\
\hline English & 14 & 21 & 14 & 5 \\
\hline Chinese & 17 & 22 & 17 & 3 \\
\hline
\end{tabular}

All the TT sentences follow the ST order except the change of line order in the middle of the page, and except for his failure to translate effectively "nor keep peace between the effect and it" (Zhu [tr.], [1944]1996: 30). An explanatory approach is also detected like in the case of "unsex me here" - the Chinese translation of which means "take away the gentleness of the fair sex." In general, Zhu translated verse by verse or sentence by sentence semantically.

\subsubsection{La Conteuse (The Story Girl)}

A comparison of pages 9, 19, 99, and 199 (Montgomery, 1993) of the French translation of The Story Girl indicates that the TT follows the ST chapters, paragraphs, and sentences closely.

TABLE 13

Paragraph and sentence arrangements in the TT of The Story Girl

\begin{tabular}{|l|l|l|l|l|l|}
\hline \multicolumn{2}{|l|}{ Source Text } & \multicolumn{4}{l|}{ Target Text } \\
\hline Selected & \multicolumn{2}{l|}{ Selected } \\
\hline Page number & Paragraphs & Sentences & Page number & Paragraphs & Sentences \\
\hline 1 & $3+1$ (inc) & 11 & 9 & $3+1$ (inc) & 11 \\
\hline $8-9$ & $2+2$ (inc) & $\begin{array}{l}12 \text { with } \\
8 \text { semicolons }\end{array}$ & 19 & $1+2$ (inc) & 20 \\
\hline 83 & 7 & 15 & 99 & 5 & 12 \\
\hline 173 & $4+1$ (inc) & 16 & 199 & $4+1$ (inc) & 16 \\
\hline & $\mathbf{1 6 + 4}$ (inc) & $\mathbf{5 4}$ & & $\mathbf{1 3 + 4}$ (inc) & $\mathbf{5 9}$ \\
\hline
\end{tabular}

While the ST contains more sentences than the TT, the TT has not changed the order of the ST sentences. The sentence-by-sentence comparability of the ST and TT indicates that the UT is the sentence.

\subsection{7. "Of Studies"}

"Of Studies" by Francis Bacon has been translated into Chinese by Dong Xu and ten other translators (see Feng, 2002: 390-406). The one-paragraph essay consists of 19 sentences including thirty-one semicolons and two colons, but the number of sentences in the Chinese translations differs - from twelve to thirty-six (Feng, 2002: 406). Needless to say, the number of semicolons in the ST indicates that the translation could potentially be rendered into fifty independent clauses. The average of the TT, however, is twenty-one sentences with 787 Chinese characters. Compare the TT means with those of the ST: 
TABLE 14

Means of sentences and words of the 11 Chinese translations of "Of Studies"

\begin{tabular}{|l|l|l|l|l|l|}
\hline & $\mathrm{N}$ & Minimum & Maximum & Mean & Std. Deviation \\
\hline TT sentences & 11 & 12.00 & 36.00 & $\mathbf{2 1 . 2 7 2 7}$ & 7.07235 \\
\hline ST sentences & 1 & 19.00 & 19.00 & $\mathbf{1 9 . 0 0 0 0}$ & \\
\hline TT characters & 11 & 612.00 & 892.00 & $\mathbf{7 8 6 . 7 2 7 3}$ & 79.56644 \\
\hline ST words & 1 & 503.00 & 503.00 & $\mathbf{5 0 3 . 0 0 0 0}$ & \\
\hline
\end{tabular}

As indicated in Table 14, the TT contains more characters than ST words. One explanation is that an English word often has to be translated into more than one Chinese character as in the case of Bacon's two-word title, "Of Studies," which was translated into three characters - "Lun $d u$ shu." The larger number of sentences in the TT, on the other hand, may be a matter of style.

What the eleven translations have in common is that each has been translated sentence by sentence and that each is individually comprehensible. The eleven translators not only follow the ST sentence order, but also the order of the clauses within the sentences in most cases. The sentence appears to be the UT.

\subsection{Poetry translation}

\subsubsection{Poetry translations by professional translators}

Contrastive analysis of a Chinese translation of Blake's “The Tiger” (Jiang [tr.], 2006: 30), a Korean translation of Meyer's "Pemberton Park" (Huh [tr.], 2005: 30), Xu's English translation of Yang's "Zong Yang Gong Wang Yue" (Xu [tr.], 1997: 30-31), two English translations of Cao's "Hao Liao Ge," entitled by Chinese readers (Cao, [1792]1992: 10) by Hawkes (Cao, 1973: 63-64 [TT1] ) and Yang and Yang (Cao and Gao, 1994: 21-22 [TT2]), among many others, reveals similar features:

TABLE 15

\section{Features of poetry translation}

\begin{tabular}{|c|c|c|c|c|c|c|}
\hline \multirow{2}{*}{\multicolumn{2}{|c|}{ Text }} & \multirow{3}{*}{$\begin{array}{l}\text { Stanzas } \\
6\end{array}$} & \multirow{3}{*}{$\begin{array}{l}\text { Lines } \\
24\end{array}$} & \multicolumn{3}{|c|}{ Punctuation } \\
\hline & & & & \multirow{2}{*}{$\begin{array}{l}\text { Commas } \\
9\end{array}$} & \multirow{2}{*}{$\begin{array}{l}\text { End marks } \\
14\end{array}$} & \multirow[t]{2}{*}{ Semicolons } \\
\hline “The Tirer" & ST: English & & & & & \\
\hline ine liger & TT: Chinese & 6 & 24 & 10 & 14 & \\
\hline \multirow{2}{*}{$\begin{array}{l}\text { "Pemberton } \\
\text { Park" }\end{array}$} & ST: English & 4 & 16 & 2 & 7 & \\
\hline & TT: Korean & 4 & 16 & 2 & 9 & \\
\hline \multirow{2}{*}{$\begin{array}{l}\text { "Zong Yang } \\
\text { Gong Wang Yue" }\end{array}$} & ST: Chinese & & 8 & 4 & 4 & \\
\hline & TT: English & & 8 & 1 & 3 & 3 \\
\hline \multirow{3}{*}{ "Hao Liao Ge" } & ST: Chinese & 4 & 16 & 7 & 9 & \\
\hline & TT1: English & 4 & 16 & 11 & 10 & \\
\hline & TT2: English & 4 & 16 & 4 & 6 & 1 \\
\hline
\end{tabular}

Table 15 indicates no change in the number of stanzas and lines. Further, the authors have found that translators closely follow the order of the lines as well as subject-verb units wherever possible. Despite the different TT punctuation marks, the TT lexical content matches that of the ST. The semantic sentence is clearly the UT. 


\subsubsection{Self-translated free verse}

Two self-translated poems, “Thirst: A Lion," and “That Word” by Zheng (1992: 196199) demonstrate an approach to translation similar to those in the section above.

TABLE 16

Features of Zheng's self-translated poems (numbers combined)

\begin{tabular}{|l|l|l|l|l|}
\hline \multirow{2}{*}{ Languages } & \multirow{2}{*}{ Lines } & Punctuation & \multicolumn{2}{|l|}{} \\
\cline { 3 - 5 } & & Commas & End marks & Semicolons \\
\hline Chinese & 36 & 8 & 0 & 0 \\
\hline English & 35 & 7 & 12 & 1 \\
\hline
\end{tabular}

The use of the period and semicolon in the middle of "That Word" demonstrates that self-translating authors take a more flexible approach to translation than translators. A translator does not always add end marks to the TT unless they are present in the ST, but Zheng adds twelve in the self-translated text. Nonetheless, in principle, Zheng's approach resembles that of the majority of translators - it is sentence-by/forsentence, or line-by-line.

\subsubsection{Bilingual author's free verse (for comparison)}

Gabrielle Roy Prize-winning author Lien Chao's free verse directly written in Chinese and English resembles translation. A sample taken from her poetry (Chao, 2004: 28-33) shows the following:

TABLE 17

Features of Chao's poems written in English and Chinese

\begin{tabular}{|l|l|l|l|l|}
\hline \multirow{2}{*}{ Languages } & \multirow{2}{*}{ Lines } & Punctuation & \multicolumn{2}{|l|}{} \\
\cline { 3 - 5 } & & Commas & End marks & Semicolons \\
\hline Chinese & 82 & 47 & 8 (in quotations) & 0 \\
\hline English & 80 & 56 & 6 (in quotations) & 0 \\
\hline
\end{tabular}

Chao's bilingual text shows more differences in syntax than the translated poems discussed previously (from Chinese to English). There are two instances where one line is split into two, and there are three cases where two lines are combined into one. There is an example of three lines reduced into two, while in two cases two lines are converted into three. The analysis suggests that translators seem to impose more restrictions on translating than writers on bilingual writing. Or there could be a possibility that authors care more about meaning than form. Despite the differences, Chao's English text matches the Chinese in sentence order. The poet appears to maximize the equivalence of meaning in the two languages sentence by sentence. Indirectly, Chao confirms the sentence as the UT. 


\section{The unit of translation confirmed}

\subsection{ST-TT converting patterns}

The contrastive analysis of the samples of translations and bilingual or multilingual texts above has identified the sentence in context as the UT. Regardless of the ST syntax, the UT - the TT sentence - is found with the following features:

- an ST complete sentence translated into a complete TT sentence,

- an ST sentence split and translated into more than one TT sentence,

- two or more ST sentences combined into a TT sentence,

- a certain number of ST components combined and translated into a TT sentence.

Over $99 \%$ of the TT sentences examined contain a clear component we call the subject-verb unit (Huang, 2002: 24). As traditionally defined, subject is what or whom the sentence talks about; verb, or predicative verb, describes what the subject does or what/who the subject is. In the English language, the subject is often immediately followed by the verb (predicate), though it may differ in other languages.

\subsection{The universal features of the UT}

The universal features of the UT in the form of a sentence are that:

- it is the smallest independent unit of comprehensible and retellable thought,

- it is the TT building block of meaning,

- unless it is poetry or informal written language, usually it has a subject-verb component,

- it ends in a period or another end mark or with some other indication,

- the meaning of the UT is assessable against the ST equivalent,

- the UT comprises the standard entity of TQA and may be assessed through a formula approach in a defined scope.

\subsection{The UT used by professional translators}

\subsubsection{How translators translate}

The responses to the first question of the international survey are shown below:

TABLE 18

Summary of translators' responses to "How do you translate?"

\begin{tabular}{|l|l|l|l|l|l|l|}
\hline \multirow{2}{*}{} & \multicolumn{7}{|c|}{ Cases } \\
\cline { 2 - 8 } & \multicolumn{2}{|c|}{ Included } & \multicolumn{2}{c|}{ Excluded } & \multicolumn{2}{c|}{ Total } \\
\cline { 2 - 8 } & $\mathrm{N}$ & Percent & $\mathrm{N}$ & Percent & $\mathrm{N}$ & Percent \\
\hline Word by word & 2 & $3.1 \%$ & 63 & $96.9 \%$ & 65 & $100.0 \%$ \\
\hline Sentence by sentence & 56 & $86.2 \%$ & 9 & $13.8 \%$ & 65 & $100.0 \%$ \\
\hline Line by line & 0 & $.0 \%$ & 65 & $100.0 \%$ & 65 & $100.0 \%$ \\
\hline Page by page & 0 & $.0 \%$ & 65 & $100.0 \%$ & 65 & $100.0 \%$ \\
\hline Other specified & 6 & $9.2 \%$ & 59 & $90.8 \%$ & 65 & $100.0 \%$ \\
\hline Other Unspecified & 1 & $1.5 \%$ & 64 & $98.5 \%$ & 65 & $100.0 \%$ \\
\hline
\end{tabular}

Note that one multiple response with three answers is excluded. As the table above indicates, $86 \%$ of the published translators translate sentence by sentence 
within context. It agrees with the analysis of the bilingual/multilingual texts presented previously. The results of the survey confirm the sentence as the UT. They are further supported by the results of a backup survey among thirty professional writers, twenty-one of whom were among the sixty-six who responded to "How do you translate?" Undeniably, $14 \%$ is still a significant percentage, even though a small minority. Further study of this group is needed to find out what their UT may be. Could the discrepancy be attributable to a lack of definition of UT in the survey (ST vs. TT)? Or could it have resulted from the respondent's wrong judgement of his or her own UT in use? (The numbers in the next section show that up to $96 \%$ often translate sentence by sentence within context.) But one thing is clear: for the overwhelming majority of translators the sentence is the UT.

\subsubsection{Percentage of translation rendered sentence by sentence}

Question 2 of the translators' survey further confirms that $87 \%$ of translators translate sentence by sentence within context more frequently than often, and that $96 \%$ often translate sentence by sentence, while $4 \%$ seldom or never translate sentence by sentence. Three invalid answers were excluded. What deserves attention is the participants' interpretation of the answers, for example, "E. Often: 50\% (or 40-59\%)." Is the hypothetical number $50 \%$ considered a "yes" or "no" answer to "Do you translate sentence by sentence?" If "often" (50\%) is a "yes" answer, there would be a $96 \%$ majority, which thus creates a discrepancy between the answers to the first and second questions. Otherwise, while the answers to Question 1 show that $86 \%$ of the translators translate sentence by sentence, Question 2 indicates that $87 \%$ translate sentence by sentence more than often ( $70 \%$ of the time), in which case, both answers confirm each other when the accuracy difference is factored in. Regardless of the possible gap, the answers to Question 2 further confirm the sentence as the UT for the overwhelming majority of translators. In percentage terms, the average translator renders $82 \%$ of his or her translation sentence by sentence within context.

TABLE 19

Translation rendered sentence by sentence by published translators (in \%)

\begin{tabular}{|l|l|l|l|l|l|l|}
\hline \multirow{2}{*}{ Percentage } & \multicolumn{6}{|c|}{ Cases } \\
\cline { 2 - 7 } & \multicolumn{2}{|c|}{ Included } & \multicolumn{2}{c|}{ Excluded } & \multicolumn{2}{c|}{ Total } \\
\cline { 2 - 7 } & $\mathrm{N}$ & Percent & $\mathrm{N}$ & Percent & $\mathrm{N}$ & Percent \\
\hline A[blank]. 2=80\%, 1=85\% & 3 & $4.8 \%$ & 60 & $95.2 \%$ & 63 & $100.0 \%$ \\
\hline B. Always: 100\% & 9 & $14.3 \%$ & 54 & $85.7 \%$ & 63 & $100.0 \%$ \\
\hline C. Usually: 95\% (or 80-99\%) & 30 & $47.6 \%$ & 33 & $52.4 \%$ & 63 & $100.0 \%$ \\
\hline D. More than often: 70\% (or 60-79\%) & 13 & $20.6 \%$ & 50 & $79.4 \%$ & 63 & $100.0 \%$ \\
\hline E. Often: 50\% (or 40-59\%) & 5 & $7.9 \%$ & 58 & $92.1 \%$ & 63 & $100.0 \%$ \\
\hline F. Less than often: 30\% (or 20-39\%) & 0 & $.0 \%$ & 63 & $100.0 \%$ & 63 & $100.0 \%$ \\
\hline G Sometimes: 15\% (or 6-19\%) & 0 & $.0 \%$ & 63 & $100.0 \%$ & 63 & $100.0 \%$ \\
\hline H. Seldom: 5\% (or less) & 2 & $3.2 \%$ & 61 & $96.8 \%$ & 63 & $100.0 \%$ \\
\hline I. Never: 0\% & 1 & $1.6 \%$ & 62 & $98.4 \%$ & 63 & $100.0 \%$ \\
\hline J. Other: (specify) & 0 & $.0 \%$ & 63 & $100.0 \%$ & 63 & $100.0 \%$ \\
\hline
\end{tabular}


It is worth noting that, excluding five invalid answers, $81 \%$ (21 of 26 ) of the published writers do $50 \%$ or more of their writing sentence by sentence, and that the average completes $63 \%$ of his or her writing sentence by sentence. The results of the survey among the students show that $90 \%$ complete $50 \%$ or more of their writing sentence by sentence, and that the average student writer completes $70 \%$ of his or her writing sentence by sentence. The two backup surveys further confirm that the sentence is the unit of writing for the majority of writers, which explains why translators make the sentence their UT. If writing is done sentence by sentence, it is only natural for translation to follow suit.

\subsubsection{How translation is evaluated and edited}

The results of the surveys also indicate that for the majority the sentence is the unit of translation evaluation and editing. Seventy-four percent of translators and translation editors indicate that they evaluate or edit translation sentence by sentence within context.

TABLE 20

How translators and editors evaluate and edit a translation

\begin{tabular}{|l|l|l|l|l|l|l|}
\hline \multirow{2}{*}{ Approaches } & \multicolumn{6}{|c|}{ Cases } \\
\cline { 2 - 8 } & \multicolumn{2}{|c|}{ Included } & \multicolumn{2}{c|}{ Excluded } & \multicolumn{2}{c|}{ Total } \\
\cline { 2 - 8 } & $\mathrm{N}$ & Percent & $\mathrm{N}$ & Percent & $\mathrm{N}$ & Percent \\
\hline Word by word & 2 & $3.3 \%$ & 59 & $96.7 \%$ & 61 & $100.0 \%$ \\
\hline Sentence by sentence & 45 & $73.8 \%$ & 16 & $26.2 \%$ & 61 & $100.0 \%$ \\
\hline Line by line & 1 & $1.6 \%$ & 60 & $98.4 \%$ & 61 & $100.0 \%$ \\
\hline Page by page & 2 & $3.3 \%$ & 59 & $96.7 \%$ & 61 & $100.0 \%$ \\
\hline Other: paragraph by paragraph & 10 & $16.4 \%$ & 51 & $83.6 \%$ & 61 & $100.0 \%$ \\
\hline All others including unspecified & 1 & $1.6 \%$ & 60 & $98.4 \%$ & 61 & $100.0 \%$ \\
\hline
\end{tabular}

As Table 20 shows, $16 \%$ of the translators or editors evaluate or edit translation paragraph by paragraph, which corresponds to the second most important group. It is likely that many translators and editors may take a multiple approach in practice, but their answers clearly indicate that they know of the primary unit of evaluation and editing, which reconfirms the sentence as the UT.

In contrast, no clear majority of writers and editors use the sentence as the primary unit of evaluation and editing. While that unit may be the sentence, the paragraph plays an even more important role in this regard. Seventeen percent (5 of 30) take a multiple approach. If the multiple answers are included and each item is calculated based on the total number of participants, $47 \%$ indicate the sentence as the unit of evaluation and editing, and 53\%, the paragraph. 
TABLE 21

Approaches to evaluation and editing

\begin{tabular}{|l|l|l|l|l|l|l|}
\hline \multirow{2}{*}{ Approaches } & \multicolumn{6}{|c|}{ Cases } \\
\cline { 2 - 8 } & \multicolumn{2}{|c|}{ Included } & \multicolumn{2}{c|}{ Excluded } & \multicolumn{2}{c|}{ Total } \\
\cline { 2 - 7 } & $\mathrm{N}$ & Percent & $\mathrm{N}$ & Percent & $\mathrm{N}$ & Percent \\
\hline Word by word & 4 & $13.3 \%$ & 26 & $86.7 \%$ & 30 & $100.0 \%$ \\
\hline Sentence by sentence & 14 & $46.7 \%$ & 16 & $53.3 \%$ & 30 & $100.0 \%$ \\
\hline Line by line & 3 & $10.0 \%$ & 27 & $90.0 \%$ & 30 & $100.0 \%$ \\
\hline Page by page & 2 & $6.7 \%$ & 28 & $93.3 \%$ & 30 & $100.0 \%$ \\
\hline Other: paragraph by paragraph & 16 & $53.3 \%$ & 14 & $46.7 \%$ & 30 & $100.0 \%$ \\
\hline All others including unspecified & 0 & $.0 \%$ & 30 & $100.0 \%$ & 30 & $100.0 \%$ \\
\hline
\end{tabular}

The student-writers' survey, on the other hand, shows that 70\% (51 of 73, excluding multiple answers) use the sentence as the primary unit, a significantly higher number than that of the writers/editors group, probably due to shorter lengths of writing. These numbers suggest that, unlike the unit of writing, that of translation evaluation and editing and that of translating, either the sentence or the paragraph could be the writers' unit of evaluation and editing, though paragraph connection and overall stylistic matters and other issues are not meant to be overlooked. As it may be interpreted, due to the likelihood that ST editing is conducted at different levels through a variety or combination of approaches, TT editing and evaluation at the sentence level may suffice to guarantee the essential quality of the ST. In other words, the ST editor may have completed much of the work regarding themes, logic, structural organization, etc., above the sentence level, which allows the translator to translate and evaluate the sentence within the textual context.

\section{Conclusion}

\subsection{Implication of this study for translatology}

The analysis of the samples selected from the two bilingual versions of the Holy Bible, a bilingual version of the Old Testament and Apocrypha, three bilingual versions of the New Testament, a trilingual New Testament with four versions of Chinese translation, two translations of the Chinese poem from Hong Lou Meng, the translation of the Nobel Prize-winning novel Soul Mountain, the translation of Confucius' Lun $\mathrm{Yu}$ into twenty-three languages, the UN Universal Declaration of Human Rights in 332 languages, the Canadian government's bilingual documents, and academic translations by scholars, in the amount of over 23,000 pages, among others, clearly indicates that the sentence in context is the UT, into which translators translate. Though translations do not resemble factory-manufactured products, more than $99 \%$, if not $100 \%$, of reputed contemporary translators follow the order of the ST sentences, paragraphs, and chapters. Though they combine and split ST sentences as required by the paramount task of translating the meaning, they follow the flow of thought and order of the events, whatever it may be, in the individual sentences wherever possible.

While we shall be happy to accept contrary results of contrastive analysis of high quality texts rendered by recognized translators (excluding isolated or accidental 
instances), we would be surprised if the sentence in context as the UT could be proved otherwise. As discussed above, our study disagrees with many previous publications that make the following claims:

- the culture is the UT;

- the entire text is the UT;

- the word is the UT;

- everything or anything could be the UT.

Our study begs to challenge the following:

- the word group is the UT;

- the clause in traditional grammar with the exception of the independent clause is the $\mathrm{UT}$;

- the paragraph is the best UT.

\subsection{Implication for future research}

Theoretically, Matthiessen's assumption that the likely candidate of the UT is the sentence (in traditional grammar terms) has been confirmed. Other scholars who have made similar assumptions also have their opinions confirmed. The implications for translation studies may be significant in many aspects. Unless the authors' analysis is proven wrong, theorists can no longer afford to create UT-related theories without recognizing the UT which this study has identified and confirmed. It is the authors' view that the translating unit is where the theorist and the practitioner meet. Thus, for a UT-related theory to be testable, the translation theorist may no longer be able to ignore or sideline the UT - the sentence in context.

\section{ACKNOWLEDGEMENTS}

Harry J. Huang wishes to thank Macquarie University whose iMURS enables him to engage in this study. Special thanks go to Christian M.I.M. Matthiessen for advice, Pauline Tan for translating the abstract, all the participants, and the reviewers of the $33^{\text {rd }}$ Conference of the Linguistic Association of Canada and the United States where this paper was originally presented.

Call for further participation: The authors invite translation scholars or translators to email them any translation rendered by a contemporary, reputed translator, published by a recognized publisher that contradicts their findings, but no isolated sentences, passages, or self-publication, please.

\section{REFERENCES}

Alı, A. Y. (tr.) (1999): The Glorious Qur'ân Translation, Scarborough, Ontario, ICNA Book Service.

Ali, A. Y. (tr.) (2002): The Meaning of the Glorious Qur'ân Translation, Istanbul, Asir Media.

British and Foreign Bible Society (1899): The New Testament of Our Lord and Saviour Jesus Christ: According to the Received Greek Text Together with the English Authorized Version, Cambridge, Printed at the University Press by J. and C. F. Clay for the British and Foreign Bible Society.

Brown, R. K. and P. W. Comfort (trs.); Douglas, J. D. (ed.) (1990): The New Greek-English Interlinear New Testament, Wheaton, Illinois, Tyndale House Publishers.

Cao, X. (1973): The Story of the Stone Vol. 1 (David Hawkes, tr.), England, Penguin Books.

CAO, X. ([1792]1992): Hong Lou Meng, Tainan, Taiwan, Shi yi wen hua shi ye gu fen you xian gong si.

CAo, X. and E. Gao (1994): A Dream of Red Mansions (Xianyi Yang \& Gladys Yang, trs.), Beijing, Foreign Languages Press. 
CAO, X. and E. GaO (1995): Hong Lou Meng, Beijing, Hua xia chu ban she.

Chan, L. T. H. (2004): Twentieth-Century Chinese Translation Theory, Amsterdam, John Benjamins.

Chao, L. (2004): More Than Skin Deep: Poetry in English and Chinese, Toronto, TSAR Publications.

Chinese TSPM and CCC (1997): Holy Bible: New Revised Standard Version/Chinese Union Version (With Simplified Chinese Characters), Shanghai, Chinese TSPM and CCC.

DAI, L. (tr.) (1982): Wu Tuo Bang (Utopia by Thomas More), Beijing, Shang wu chu ban she.

Department of Justice (1982): The Canadian Charter of Rights and Freedoms, Ottawa, Government of Canada.

Editorial Board (2006): The Lun Yu, Confucius Publishing, <www.confucius.org >.

Eliasee, M. A. H. [transliteration in Roman Script] and M. M. Pickthall (tr.) (2001): The Holy Qur'aan: Transliteration in Roman Script and English Translation, New Delhi, Islamic Book Service.

Feng, Q. (2002): Shi Yong Fan Yi Jiao Cheng (Ying Han Hu Yi) Zeng Ding Ben (A Practical Coursebook on Translation), Shanghai, Shanghai Foreign Language Education Press.

GAO, X. (2000a): Ling Shan, Hong Kong, Cosmos Books.

GAO, X. (2000b): Soul Mountain (Mabel Lee, tr.), New York, Perennial.

GAO, X. (2003): Soul Mountain (2nd ed.) (Mabel Lee, tr.), New York, Harper Perennial.

Government of China (1992): Patent Law of the People's Republic of China (in Chinese and English), Beijing, Zhuan li wen xian chu ban she.

Guo, J. (2002): "Han Yi Ying De Fan Yi Dan Wei Wen Ti" (“The UT in Chinese-English translation"), Ying Han Yu Bi Jiao Yu Fan Yi (English-Chinese comparative study and translation), Shanghai, Shanghai Foreign Language Education Press, pp. 540-559.

Halliday, M. A. K. (2002): "Ji Suan Yi Yi: Hui Gu Guo Qu, Zhan Wang Wei Lai” (“Computing Meanings: Some Reflections on Past Experience and Present Prospects") (Canzhong Wu, tr.), in HuAng, G. (ed.), Discourse, Language Functions and Language Teaching, Guangzhou, Zhongshan University Press, pp. 1-31.

Hatim, B. and I. Mason (1990): Discourse and the Translator. Essex, Longman.

Hatim, B. and J. Munday (2004): Translation: An Advanced Resource Book, London and New York, Routledge.

Hong Kong Bible Society (1992): Holy Bible: King James Version/Chinese Union Version with New Punctuation, Hong Kong, Hong Kong Bible Society.

Huang, H. J. (1986): Zen Yang Biao Dian Ying Yu Ju Zi (How to punctuate the English sentence), Nanning, Guang xi ren min chu ban she.

Huang, H. J. (2002): Jian Ming Ying Yu Ju Fa Ji Ju Zi Xie Zuo (Highlights: simple sentence skills), Beijing, Foreign Languages Press.

Hun, D.-T. (tr.) (2005): "Pemberton Park" by Bruce Meyer, Variety Crossing $7^{\text {th }}$ Volume, Toronto, KCLFP-21, pp. 30-31.

JiAng, J. (tr.) (2006): "Lao Hu" (“The Tiger" by William Blake), The World of English 25-1, p. 30.

Lederer, M. 2003. Translation: The Interpretive Model (N. Larche, tr.). Manchester: St. Jerome Publishing.

Marshall, A. (tr.) (1960): The Interlinear Greek-English New Testament: The Nestle Greek Text with a Literal English Translation, London, Samuel Bagster and Sons.

Matthiessen, C. M. I. M. (2001): "The Environments of Translation," in E. Steiner and C. YAllop (eds.), Exploring Translation and Multilingual Production: Beyond Context, Berlin and New York, Mouton de Gruyter, pp. 127-160.

Montgomery, L. M. ([1944]1987): The Story Girl, Toronto, McClelland-Bantom.

Montgomery, L. M. (1993): La Conteuse (The Story Girl) (Helene Rioux, tr.), Québec, Éditions Québec/Amérique.

More, T. (1965): “Utopia," The Complete Works of St. Thomas More (Latin-English), New Haven and London, Yale University Press. 
Nadvi, A. Ali (tr.) (2001): Le Saint Coran, Delhi, Kutub Khana Ishayat-UL-Islam.

Nord, C. 1991. Text Analysis in Translation: Theory, Methodology, and Didactic Application of a Model for Translation-Oriented Text Analysis (C. Nord and P. Sparrow, trs), Amsterdam and Atlanta, Rodopi.

Nord, C. [1997] 2001. Translating as a Purposeful Activity: Functionalist Approaches Explained. Shanghai: Shanghai Foreign Language Education Press.

P'U, S.-l. [Pu Songling] (1946): A Selection from the Liao Chai Stories (Rose Quong, tr.), New York, Pantheon.

Pu, S. (1975): Liao Zhai Zhi Yi (A collection of weird stories), Gaoxiong, Taiwan, da zhong chu ban she.

Robinson, D. (1997): Western Translation Theory: From Herodotus to Nietzsche, Manchester, St. Jerome Publishing.

Snell-Hornby, M. (1988/1995): Translation Studies: An Integrated Approach. Amsterdam/ Philadelphia, John Benjamins.

Su, P. (1999): Biao Dian Fu Hao Shi Young Shou Ce (A practical guide to the use of punctuation), Beijing, yu wen chu ban she.

United Bible Societies (1997): The Parallel New Testament: Greek New Testament, Chinese Union Version with New Punctuation, Today's Chinese Version (Revised), Lu Chen-chung Version, Studium Biblicum Version (Catholic), New Revised Standard Version, Hong Kong, Hong Kong Bible Society.

United Nations (2006): Universal Declaration of Human Rights, Geneva, The United Nations Office of the High Commissioner for Human Rights.

Vinay, J. P. and J. Darbelnet (1958/1995): Stylistique comparée du français et de l'anglais. Méthode de traduction (Comparative Stylistics of French and English: A Methodology for Translation) (J.C. Sager and M.-J. Hamel, trs. and eds.), Amsterdam/Philadelphia, John Benjamins.

Williams, M. (2004): Translation Quality Assessment: An Argumentation-Centred Approach, Ottawa, University of Ottawa Press.

Wu, C. (1990): Journey to the West (W.J.F. Jenner, tr.), Beijing, Foreign Languages Press.

Wu, C. (1995): Xi You Ji, Xian, San qin chu ban she.

Xu, Y. (1997): Golden Treasury of Yuan, Ming, Qing Poetry, Beijing, Peking University Press.

Zheng, M. (1992a): “That Word," in TANG, C. and L. Robinson (eds. \& trs.), New Tide: Contemporary Chinese Poetry, Toronto, Mangazin Books, pp. 198-199.

Zheng, M. (1992b): “Thirst: A Lion," in TAng, C. and L. Robinson (eds. and trs.), New Tide: Contemporary Chinese Poetry, Toronto, Mangazin Books, pp. 196-197.

Zhou, Z. (2004): "Writing to Defame" (David Pollard, tr.), Chinese Translators Journal 25-4, pp. 91-93.

Zhu, S. (tr.) ([1944]1996): Ma Ke Bai <Zhong Ying Dui Zhao > (Macbeth by William Shakespeare in English and Chinese), Taipei, Taiwan, The World Book Company.

Zondervan (1975): The Septuagint Version of the Old Testament and Apocrypha: With an English Translation and with Various Readings and Critical Notes, USA, Zondervan. 